\title{
Interpretation of seizure evolution pathways via a mean-field cortical model
}

\author{
Vera M Dadok ${ }^{1 *}$, Andrew J Szeri ${ }^{1,2}$, Heidi Kirsch ${ }^{3}$, Jamie Sleigh ${ }^{4}$, Beth Lopour ${ }^{5}$ \\ From Twenty First Annual Computational Neuroscience Meeting: CNS*2012 \\ Decatur, GA, USA. 21-26 July 2012
}

Treatment of epilepsy is a challenging task. Difficulties arise in choosing the best pharmaceutical drugs for specific patients, and if limited benefits result, attempting to choose the best alternative treatment. It is not always clear why a treatment that works well for one patient does not work well for another. Better understanding of the epileptic brain, such as differentiating between possible biologi- cal mechanisms driving seizure evolution, may offer insight into these problems.

This work makes use of a dynamical model of the human cortex based on the underlying physiology and local anatomy of the brain [1]. This mean-field model can generate electrocorticogram-like (ECoG-like) data in both normal states and seizing states under different plausible

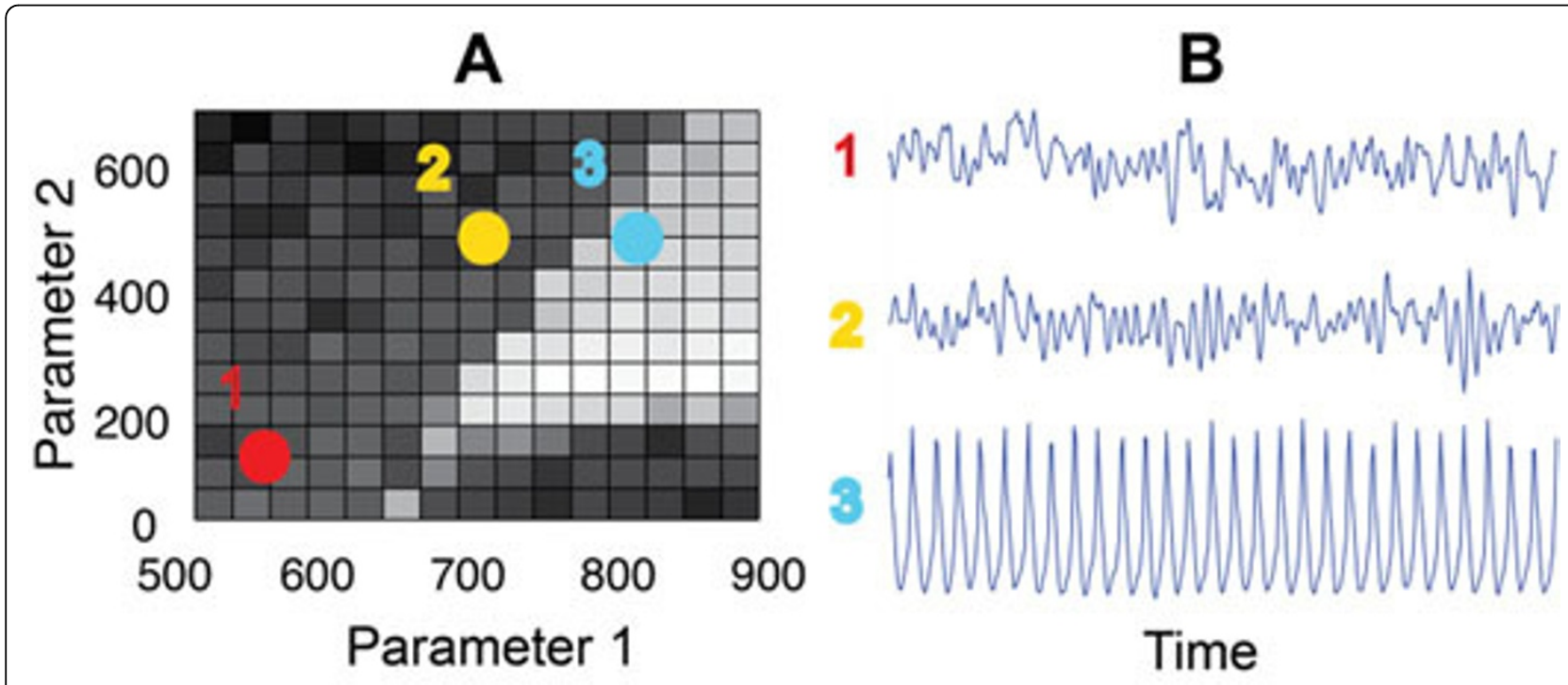

Figure 1 Illustrates a possible path via two model parameters varying and the resultant ECoG-like data. The exact definitions of all parameters are left to the poster. In this illustrative figure parameter 1 is related to the number of inhibitory synaptic connections and parameter 2 is related to the strength of the subcortical input on excitatory neurons in the cortex. $\mathbf{A}$. Locations in parameter space. Shading relates to the permutation complexity of the signal. B. ECoG-like data signals generated by the model corresponding to locations in parameter space. At locations 1 and 2, the simulated signal through time shows normal cortex activity. At location 3, the ECoG-like data signal through time is in a seizure state with more regular sustained oscillations.

\footnotetext{
* Correspondence: vdadok@berkeley.edu

${ }^{1}$ Department of Mechanical Engineering, University of California, Berkeley, CA 94720, USA

Full list of author information is available at the end of the article
} 
parameter configurations [2,3]. There are several different sets of parameters which, when changed, drive the model from a non-seizing state into a seizing state and back. An example of one such pathway is displayed in Figure 1. The presence of different parameter sets that can trigger seizures or exit seizures when varied indicates that there are different biological pathways to and from seizure, and these pathways can be described in terms of the fundamental physical quantities in the model [2]. This work will demonstrate a method that takes ECoG-like data from a model cortex evolving into seizure and identifies which parameters are changing-thus identifying which associated physiological mechanisms may be leading the brain into a seizure. In conjunction with other tools, this method will leverage feature selection and dimensionality reduction algorithms. The same technique may be applied to experimentally collected ECoG seizure data as well.

\section{Acknowledgements}

This work was partly supported by a research grant from the National

Science Foundation and an NSF Graduate Research Fellowship to V. Dadok.

\section{Author details}

'Department of Mechanical Engineering, University of California, Berkeley, CA 94720, USA. ${ }^{2}$ Center for Neural Engineering and Prostheses, UC Berkeley and UC San Francisco, CA, USA. ${ }^{3}$ School of Medicine, University of California, San Francisco, CA, 94143, USA. ${ }^{4}$ School of Medicine, University of Auckland, Grafton, Auckland, 1142, New Zealand. ${ }^{5}$ Department of Neurobiology, University of California, Los Angeles, CA, 90095, USA.

Published: 16 July 2012

\section{References}

1. Steyn-Ross ML, Steyn-Ross DA, Sleigh JW, Whiting DR: Theoretical predictions for spatial covariance of the electroencephalographic signal during the anesthetic-induced phase transition: Increased correlation length and emergence of spatial self-organization. Phys Rev E 2003, 68:021902-1021902-18.

2. Kramer MA, Szeri AJ, Sleigh JW, Kirsch HE: Mechanisms of seizure propagation in a cortical model. J. Comput Neurosci 2007, 22:63-80

3. Loupour BA, Tasoglu S, Kirsch HE, Sleigh JW, Szeri AJ: A continuous mapping of sleep states through association of EEG with a mesoscale cortical model. J. Comput Neurosci 2011, 30:471-487.

doi:10.1186/1471-2202-13-S1-P95

Cite this article as: Dadok et al: Interpretation of seizure evolution pathways via a mean-field cortical model. BMC Neuroscience 201213 (Suppl 1):P95.

\section{Submit your next manuscript to BioMed Central} and take full advantage of:

- Convenient online submission

- Thorough peer review

- No space constraints or color figure charges

- Immediate publication on acceptance

- Inclusion in PubMed, CAS, Scopus and Google Scholar

- Research which is freely available for redistribution

Submit your manuscript at www.biomedcentral.com/submit 